\title{
O nascituro como pessoa humana: a constituição e o código civil como fundamentos para a pessoalidade do embrião humano
}

\author{
The unborn as human person. The constitution and civil law as foundations to the \\ personhood of the human embryo
}

El nacimiento como persona humana: la constitución y el código civil como fundamentos para la personalidad del embrión humano

Samuel de Jesus da Silva Lobato ${ }^{1 *}$, Victor Sales Pinheiro ${ }^{1}$

\begin{abstract}
RESUMO
Objetivo: Abordar a questão da pessoalidade do nascituro e seu reconhecimento como pessoa humana, levando em conta, dentro outros aspectos, dados biológicos e filosóficos acerca do não nascido. Ato contínuo, pretende fazer um breve levantamento da constituição federal do Brasil de 1988 e do código civil brasileiro, buscando destacar a condição do não nascido dentro destes textos legais. Assim feito, faz-se um breve comentário dentro dos tópicos legais acerca das consequências da aceitação deste status de pessoalidade ontológica para o direito. Revisão bibliográfica: Partindo de dados pré estabelecidos, como códigos e conjunto de leis, far-se-á uma investigação interdisciplinar das premissas filosóficas, biológicas e bioéticas acerca da natureza humana do embrião e as consequências lógicas para a recepção ou não do embrião como pessoa humana. Considerações finais: Quando levados em conta os aspectos biológicos, filosóficos, bioéticos e legais, o embrião é pessoa humana que detém dignidade igual a de qualquer outro membro da mesma espécie, independentemente de seu estágio de desenvolvimento ou maturação e a lei, a grosso modo, deve resguardar sua integridade física e moral, bem como seus direitos.
\end{abstract}

Palavras-chave: Nascituro, Constituição federal, Código civil, Direito, Vida.

\begin{abstract}
Objective: To approach the problem of the personhood of the unborn and it's acknowledgement as a human person considering, among other things, biological and philosophical data about the unborn. Hein pretends to make a brief engage on the Federal Constitution of Brazil of 1988, e the Civil Code of Brazil, trying to push forward the condition of the unborn inside these legal texts. Therefore, it is make a brief comment about the legal topics, which bring up the consequences of the acceptation of this status of ontological personhood for the Law. Literature review: Going from pre-established data, like codes and set of law, an interdisciplinary research of the philosophical, biological and bioethical premises about the nature of the human embryo and the logical consequences for the acceptation or not for the unborn as human person, will be done. Final considerations: When the biological, philosophical, bioethical, and legal issues are considered, the embryo is a human person that holds dignity equal as any other member of the same species, regardless of his stage of development, maturation. And the law, generally, must protect its moral and physical integrity, and its rights.
\end{abstract}

Key words: Unborn, Federal constitution, Civil law, Law, Life.

\section{RESUMEN}

Objetivo: Abordar la cuestión de la personalidad del feto y su reconocimiento como persona humana, teniendo en cuenta, en otros aspectos, los datos biológicos y filosóficos sobre el no nacido. A continuación, tengo la intención de hacer una breve encuesta de la Constitución Federal brasileña de 1988 y el Código Civil brasileño, buscando resaltar la condición de los no nacidos en estos textos legales. Por lo tanto, se hace un breve comentario, dentro de los temas legales sobre las consecuencias de la aceptación de este estado de personalidad ontológica a la ley. Revisión bibliográfica: A partir de datos preestablecidos, como códigos y

1Universidade Federal do Pará (UFPA), Belém -PA. *E-mail: samuellobatosdm@gmail.com 
conjunto de leyes, se realizará una investigación interdisciplinaria de las premisas filosóficas, biológicas y bioéticas sobre la naturaleza humana del embrión y las consecuencias lógicas para la recepción del embrión o no cómo persona humana. Consideraciones finales: Cuando se tienen en cuenta los aspectos biológicos, filosóficos, bioéticos y legales, el embrión es una persona humana que tiene la misma dignidad que cualquier otro miembro de la misma especie, independientemente de su etapa de desarrollo o maduración y la ley, en términos generales, deben salvaguardar su integridad física y moral, así como sus derechos.

Palabras clave: No nacido, Constitución federal, Código civil, Derecho, Vida.

\section{INTRODUÇÃO}

A pessoalidade do nascituro, bem como sua personalidade civil possuem um impacto grande na sociedade contemporânea. Um posicionamento concreto a respeito desta temática implicaria em um posicionamento que, se definitivo, seria controverso independentemente da conclusão que se chegasse. A realidade é que 0 debate sobre este tema é repleto de paixões, motivadas por razões distintas, de quem defende ou rejeita 0 aborto (KACZOR C, 2014).

A questão do aborto no Brasil é permeada por discussões que turvam uma abordagem objetiva da problemática. É mister, no contexto atual, que haja uma abordagem acerca disso sob uma ótica embasada em dados científicos em torno da natureza do embrião humano, sua pessoalidade e dignidade. Tudo isso dentro do eixo do conjunto de leis nacionais, em especial, a Constituição Federal de 1988, que é a Lei Maior do país (MARTINS IGS, 2005).

No Brasil há uma tentativa recorrente de ampliar o acesso ao aborto, justificando o ato abortivo por motivos distintos. Desde uma anencefalia (BRASIL, STF, ADPF 54, 2012) até uma possível microcefalia advinda de uma gestação maculada pelo Zika Vírus (BRASIL, ADI 5581, 2016). Essas incursões de legalização do abortamento ocorrem para ampliar o rol de possibilidades não puníveis de aborto já presentes no Código Penal, que são em caso de estupro, risco a saúde da mãe e fetos anencéfalos, este último possível devido a ADPF 54 (BRASIL, Código Penal, 1941).

Não obstante, parece haver uma séria contradição do que está disposto na Lei Maior do país com a crescente judicialização de questões que envolvem a chamada interrupção voluntária da gravidez. A constituição federal do Brasil resguarda o direito à vida e, quando lida em consonância com o Pacto São José da Costa Rica, retifica esse compromisso inclusive com os não nascidos. Isto demonstra que há uma incompatibilidade entre tal demanda e realidade disposta na norma (MARTINS IGS, 2005).

Ato contínuo o nascituro também possui direitos de personalidade jurídica previstos nos Código Civil e que corroboram a afirmação de que o não nascido deve ter seu direito à vida respeitado já que, como possuidor de direitos sucessórios, dentre outros, não outra coisa que não um ser humano detentor de direitos e, por isso, deve ter sua integridade física respeitada e protegida (DINIZ MH, 2007).

Diante dessas informações, investiga-se, em forma de revisão narrativa, como o nascituro é tido no contexto da literatura jurídica presente, em especial, na constituição federal, código civil e trabalhos versados em filosofia do direito, bioética e biodireito e, espera-se contribuir para a reflexão em torno desta temática que não perde sua relevância.

\section{REVISÃO BIBLIOGRÁFICA}

\section{A constituição e o direito à vida do nascituro}

A Constituição Federal (CF) em seu artigo $5^{\circ}$ (BRASIL, 1988), que trata dos direitos fundamentais, rege a proteção em especial ao Direito à Vida, bem como a liberdade, igualdade, segurança e propriedade. Estes são chamados de primeira geração dos direitos fundamentais (CARVALHO KG, 2009). Apesar de não existir direito absoluto, o direito à vida é fundamental e só pode ser confrontado quando há risco à própria vida, ou seja, quando há uma colisão de direitos fundamentais, como é o caso de legítima defesa, de guerra, e de preservar a saúde da mãe em gravidez de risco (CARVALHO KG, 2009). Este problema surge ao se 
considerar a pessoalidade e dignidade do embrião humano, já que este passaria a ser detentor de proteções mais abrangentes quanto a sua integridade física e moral (BICUDO H, 1997).

A vida começa no momento da concepção (GEORGE RP, 2016). Aí já existe um ser humano relativamente autônomo que se desenvolverá e mudará apenas em sentido evolucionário gradativo. Geneticamente, não há qualquer diferenciação do não nascido para com um homem adulto (GEORGE RP, 2016). Seguinte a essa informação, desenvolveram-se teorias, mais jurídicas e filosóficas que biológica/médica, para atestar quando passa a existir uma pessoa humana detentora de direitos. As teorias são a da concepção, nidação, implementação do sistema nervoso e, por fim, a teoria dos sinais eletrencefálicos (RODRIGUES FILHO AMM, 2018).

As teorias que debatem quando tem início a vida não pesam no que tange às decisões do Supremo Tribunal Federal (STF) a respeito do tema (STF, ADPF 54, 2012). O embrião, para a Suprema Corte brasileira, não é indivíduo pessoa, de modo que não se encontra amparado pela norma constitucional, portanto, não é detentor de direito fundamental, já que é tido como bem, e não como pessoa humana (STF, ADI 3510, 2008). O STF ainda distingue que embrião, feto, e pessoa humana são coisas distintas (STF, ADI 3510, 2008) sem, entrar no mérito do que é distinguível entre essas fases do desenvolvimento humano, que não seja morfológico.

A posição do STF é contraditória, já que o Estado brasileiro, no Caput do art. $5^{\circ}$ reconhece e garante o direito à vida humana, sem fazer distinção alguma (BRASIL, 1988, art. 5ํ). Nem mesmo fala em pessoa, mas em brasileiros e estrangeiros, e que todos são iguais perante a lei, garantindo assim qualquer vida humana "ainda que imperfeita, ainda que submetida a limitações, a vida de qualquer criatura humana está protegida pela ordem fundante. Vida sem qualificativos" (NALINI JR, 1999). O legislador da CF precisa, e assim o fez, respeitar dados de uma interdisciplinaridade para moldar a constituição e esta não pode ser alheia aos dados sociológicos, científicos, culturais e etc., de modo a contemplar o que se pode chamar de supraconstitucionalidade autogenerativa (NALINI JR, 1999), que respeita informações obtidas em outras áreas para elaborar o próprio direito. $\mathrm{E}$ a vida, cientificamente falando, começa na concepção. A respeito disto alguns fatos são completamente incontestáveis do ponto de vista biológico, como o ser humano passar a existir a partir da fecundação, o zigoto possuir informação genética única e o embrião ter uma vida intensa desde seu surgimento (PIMENTEL MMG, 1997).

Todos estes fatos, comprovados pela ciência (LEE P e GEORGE RP, 2008), devem, ou ao menos deveriam, ser levados em conta quando se legisla e decide sobre temas que envolvem outros campos que não contemplam apenas o jurídico. Importante destacar este fato de interdisciplinaridade já que, para o Ministro Marco Aurélio, as outras ciências por serem imprecisas e mutáveis em determinadas situações não podem estabelecer diretrizes que vinculem outras áreas, como o direito (STF, ADPF54, 2012).

Convém ressaltar ainda que tal argumento é contraditório, visto que, a decisão manejada pelo STF teve como arcabouço de fundamentação dados científicos contrários entre si de tal maneira que, independentemente da decisão a qual fosse proferida, deveria necessariamente estar embutida de valores aceitos pela comunidade científica com a consequência de não ser aceita sua fundamentação (STF, ADPF 54, 2012). Escolheu-se um lado e se decidiu. Mas a decisão per si foi fundamentada em bases de outras áreas que não o Direito. Outrossim é então claro que o "constituinte não formula soluções desvinculadas das coisas", de tal forma que, se o fizesse, feriria limitações implícitas ao Poder Constituinte (NALINI JR, 1999).

Tudo isto implica que o ser humano deve ter seus direitos respeitados desde o momento em que passa a existir, ou seja, desde a concepção (MARTINS IGS, 2005). A ciência, de modo geral, já explicitou que a vida começa a partir do momento da fecundação e que ali já existe um novo indivíduo (KACZOR C, 2014). Negar o atributo de pessoa a um indivíduo é um erro já cometido pelo homem, em momentos como a escravidão e o holocausto, nos quais, as vítimas eram tidas como humanos, mas não pessoas (MARTINS RVS, 1991).

A capacidade de ser sujeito de direitos e deveres lhe cabe constitutivamente, pelo mero fato de ser homem não importando em que fase de desenvolvimento encontra-se. O momento em que o homem nasce, embora possua uma importância significativa, não constitui uma mudança de espécie ou substância individual 
(GEORGE RP, 2016). Em outras palavras, em nada se difere o que já nasceu do não nascido a não ser pelo ambiente ou fase de desenvolvimento, de forma análoga a que uma criança é diferente de um adulto ( $D$ ' AGOSTINO F, 2006).

É indispensável reforçar que o homem, só pelo fato de ser humano, já dispõe de capacidade jurídica de ser sujeito de direitos e de deveres e que a cada homem essa capacidade não é outorgada pelo Estado, mas é intrínseca a qualquer homem (D' AGOSTINO F, 2006). E, também, diferente dos antepassados que viviam sob a égide do direito romano que não reconhecia o direito a determinados grupos, cada indivíduo humano é detentor de direitos (D' AGOSTINO F, 2006).

Ato contínuo, muito se debate acerca do direito da mãe de decidir o futuro de sua prole, pelo chamado direito a saúde (D' AGOSTINO F, 2006), bem como até onde iria o direito do pai de intervir em decisão contrária ou de apoio. Como foi mostrado, em nada isso deveria influenciar na questão objetiva do abortamento, assim como do direito, visto que este, nunca é neutro (STF, ADPF 54, 2012), mas sempre tende a proteger àqueles que não podem falar por si, que dispõem de formas limitadas de comunicação ou que nem mesmo podem expressar-se devido uma condição limitadora de sua capacidade de relação social.

Interessante destacar que, no direito Italiano, tal como na atual conjectura do brasileiro, a mãe detém todo o poder de decisão sobre o feto, e a figura paterna, que obviamente teve participação na geração do novo ser, é completamente excluída do processo decisório acerca de seu filho (D' AGOSTINO F, 2006). Todavia, recentemente, em contrariedade com o que foi acima apresentado, uma decisão da justiça do Uruguai colocou isto em pauta quando através de um recurso, uma mulher foi impedida de prosseguir com o aborto (URUGUAY, Tribunal de Apelaciones de Familia de Primer Turno, 2017), recurso este que foi impetrado pelo pai da criança por nascer. Apesar da fundamentação estar baseada no descumprimento de requisitos formais necessários para levar adiante a possibilidade do aborto, é uma decisão provocada por uma ação advinda do genitor do feto, de tal modo que se levantou novamente o papel da participação paterna no que diz respeito ao destino do concebido (URUGUAY, Tribunal de Apelaciones de Familia de Primer Turno, 2017).

Contudo, apesar do direito concedido à mulher que tem como premissa direito à saúde sexual e reprodutiva, a discussão sobre a questão do aborto não se findou. A razão para a permanência do embate que envolve de um lado os grupos chamados "Pró-vida" e de outro os defensores do "direito de escolha da mulher", recai numa premissa que a lei não pode extinguir (KACZOR C, 2014). A questão envolve diversos setores acadêmicos e sociais. Na verdade, há de se pensar se o problema que engloba o aborto foi de fato resolvido ou se apenas foi removido (D'AGOSTINO F, 2006). A questão é profunda, pois envolve sempre um terceiro que é tomado em um cabo de guerra entre diversos setores, cada um interessado em defender sua perspectiva, por diversas motivações, e muitas vezes esquecem que o nascituro, como já demonstrado, é um ser humano o qual pela sua própria condição ontológica tem garantida sua integridade física e moral e, por decorrência disto, também é indivíduo e pessoa, ainda que tenha sua capacidade limitada por fatores que independem de sua vontade, como desenvolvimento intrauterino e externo (GEORGE RP, 2016).

A identidade do embrião é na verdade o cerne de toda a questão. O embrião como ser autônomo também é dotado de subjetividade. Um exemplo que pode ser dado é no caso de um embrião, fecundado in vitro, que não possua possibilidade de rastrear seus progenitores genéticos. Sua subjetividade será a única restante (D' AGOSTINO F, 2006). Isto ocorre desde a concepção, e o torna uma pessoa única que, independente de fase de desenvolvimento, deve ter sua vida preservada, segundo a CF (BICUDO H., 1997). Em resumo, a vida, de acordo com a Constituição Federal Brasileira de 1988, "seja biológica, seja moral, ou juridicamente, começa desde a concepção" (NALINI JR, 1999).

\section{O embrião como detentor de direitos}

Conceituar pessoa é uma tarefa árdua que mesmo a ciência evita por não ser passível de reconhecimento, uma vez que pessoa não pode ser apreendida em um conceito (BARZOTTO LF, 2010). Contudo, ao considerar então que o embrião é uma pessoa humana e não uma potencialidade de pessoa, a questão a ser enfrentada é se este possui direitos a serem resguardados. Existem diversos usos do embrião que são promissores do ponto de vista cientifico, como a promessa de cura de câncer e diabetes, coisas que, apesar 
de promissoras, fogem a realidade, já que a utilização de células tronco embrionárias para fins medicinais não apresentaram nenhum progresso, e sim, fracasso (MARTINS IGS, 2005) e outros usos mais triviais que já são comuns, como o a fertilização in vitro, o que implica diretamente na utilização de embriões em procedimentos científicos.

No caso em que ocorre o cerceamento à vida e ao desenvolvimento natural do ser humano em fase embrionária, ocorre a inversão da lei e do papel do estado, quando a vida é passiva de ser aniquilada, pelo poder juridicamente respaldado, e o poder jurídico torna o ser humano vivente excluído e passível de aniquilação (MARTINS AS, 2015). Existe aí um conflito latente entre jusnaturalismo e o positivismo jurídico, entre um direito inerente a própria natureza humana e a letra da lei (MARTINS IGS, 2005).

O embrião, então sendo detentor de direitos, não pode ser meio para um fim. A célebre máxima Kantiana de que o ser humano é um fim em si mesmo (KANT I, 2004) acaba por estender-se ao não nascido de maneira completa. Ignorar isso seria novamente reduzir a dignidade do mesmo. Por conseguinte, qualquer uso deste para fins que visem não o seu próprio bem, mas que venham a lhe acarretar prejuízo e até sua aniquilação devem ser rejeitadas (ESPINOSA J, 1998). Caso isto não ocorra, o embrião humano acabará por tornar-se alvo de comércio (como em alguns casos já o é - fertilização in vitro-) e passíveis de manipulação genética com fins eugênicos (ESPINOSA J, 1998).

Outra consequência seria a lógica conseguinte de que se o ser humano é passível tanto de comercialização quanto de experimentação na sua fase embrionária, também o seria em outras fases de seu desenvolvimento. A utilização de fetos, de crianças recém-nascidas, ou até mesmo de jovens e adultos indesejados (como as pessoas com deficiências mentais) seria perfeitamente válida. Nada impede que isto aconteça, já que a justificativa de um bem maior a ser alcançado continuaria coerente, bem como a desconsideração da pessoa humana (GEORGE, TOLLEFSEN, 2011). A problemática maior incorre quando, ao se instrumentalizar o ser humano, se perde a noção de dignidade do mesmo. Outra questão é o que caracterizaria um ser humano pleno, já que a corrida utilitarista por uma perfeição justificaria a própria Eugenia. Pode-se exemplificar recordando o caso chamado tuskegee. Este foi um estudo que utilizava negros como cobaias para se verificar o desenvolvimento de sífilis e os submetidos ao estudo não tinham conhecimento sequer que eram portadores da doença (ESPINOSA J, 1998).

Em suma, a utilização de seres humanos, independente da fase natural em que se encontram para fins que agridam a sua dignidade, sempre abrem portas para riscos de expansão (LEÃO P, 2005). Quando se é permissivo para com a manipulação e instrumentalização do ser humano, desconsiderando seu direito natural, e por extensão, tudo o que advém deste, como dignidade, individualidade, liberdade, surgem janelas que dão vazão à novas formas de exploração, escravidão e manipulação do ser humano (ESPINOSA J, 1998). Com base no exposto, é pertinente que o embrião assim como qualquer ser humano, novo, jovem, velho, com deficiência física ou mental, possui intrinsecamente direitos naturais a serem resguardados de forma positiva, de modo que não venham a ser molestados com base em justificativas relativistas e utilitaristas que os reduzam a meros instrumentos ou meios para que se atinja um fim, independentemente da suposta boa-fé da intenção que sombreia o cerceamento de direitos a seres humanos.

\section{O nascituro e código civil}

O Código Civil (CC) Brasileiro toca algumas vezes na questão do nascituro, de modo explícito em alguns artigos, quando põe a salvo direitos próprios deste, a sabe em seus artigos 2, 542, 1.778 e 1779 (BRASIL, Código Civil, 2002). O legislador, quando assim redigiu o CC, pensou, obviamente, que o nascituro não somente é ser humano como, também, pessoa capaz de personalidade jurídica formal. Esta personalidade jurídica diz respeito àqueles direitos que resguardados constitucionalmente, garantem ao não nascido personalidade jurídica material se nascer com vida, ocasião em que será titular daqueles direitos que até então, estavam em estado potencial (DINIZ MH, 2007).

A legislação brasileira não contempla a possibilidade de fazer herdeiros os animais ou seres que não o humano. Não é possível deixar herança para um cachorro ou gato, nem para um objeto inanimado, o que faria menos sentido ainda. Porém, ao nascituro não só é possível, como este pode tornar-se titular de bens 
que serão ipsu facto seus quanto atingir a idade necessária para regê-los (BRASIL, 2002). Isto demonstra que não há como sobrepor ao direito e o respeito à vida, sem o qual nenhum outro pode subsistir de forma segura, o aborto, independentemente da motivação que suscite a iniciativa para promovê-lo ou executá-lo, seja por viés políticos, particulares ou ideológicos (DINIZ MH, 2007).

Não há também, possibilidade de admitir o aborto premeditado, de modo que a mulher engravide já com intenção de abortar para obter do feto substâncias diversas que vão desde usar a medula espinhal visando combater leucemia em outro filho, como também para utilizar a placenta como fonte de tratamento de beleza, em forma de cosmético (DINIZ MH, 2007). Condutas como estas transformam o ser humano em mero meio para um fim, e fazem do feto um mero objeto que pode ser utilizado como qualquer bem móvel ou imóvel, uma pertença de alguém. Isto fere absurdamente a dignidade do indivíduo como pessoa humana (DINIZ MH, 2007).

Existem diversos casos em que é suscetível a indenização por danos morais ao nascituro, seja por ofensa a sua integridade física ou mental. Vale destacar alguns como Manipulação genética, Experiência cientifica, Comercialização de embriões excedentes (DINIZ MH, 2007, LICHFIELD M, KENTISH S, 1977). Estes são alguns casos em que há a possibilidade de indenização devida ao nascituro. Isto demonstra que não é um bem perecível ou passível de manipulação que implique em denegrir sua dignidade de pessoa humana (DINIZ $\mathrm{MH}, 2007)$.

Isto aponta para um crescente rol dos direitos do nascituro, independente, como já dito, do vínculo parental. O não nascido então: não pode ser usado para fins lucrativos, tem direito ao pai ou à paternidade certa, possui direito a alimentos e detém direito à honra (DINIZ MH, 2007; BICUDO HP, 1997). Os direitos acima listados mostram que, além de inúmeros, o nascituro é sujeito de direito e, de acordo com o Código Civil Brasileiro, tal como a Constituição Federal, um ente dotado de personalidade jurídica formal e material (DINIZ MH, 2007).

\section{CONSIDERAÇÕES FINAIS}

O nascituro é pessoa humana. Desde a concepção até seu fim natural, há uma dignidade intrínseca ao mesmo. Não há mudança genética nenhuma ou qualquer fator natural, a não ser o próprio desenvolvimento natural, que não implica em mudança ontológica da natureza, que possa justificar uma "despessoalização" deste. O direito, a partir da constituição brasileira, já reconhece o direito à vida a todos os cidadãos brasileiros e estrangeiros, não havendo nenhuma exceção, salvo em estado de guerra. Por conta disso, se pode afirmar que o embrião humano, é sim detentor de direitos humanos básicos, dentre estes, o direito a não ter sua vida ceifada arbitrariamente por motivos que lhe são alheios, por mais delicados que sejam.

\section{REFERENCIAS}

1. ALBUQUERQUE RC de, JÚNIOR AJP. A guerra contra os mais fracos: a lei de prevenção de Doenças Hereditárias, o programa de eutanásia e o totalitarismo alemão. O aborto do anencéfalo no Brasil. in MARTINS, Ives Gandra da Silva (coordenação). Direito Fundamental à Vida. São Paulo: Quartier Latin/ Centro de Extensão Universitária, 2005.

2. BARZOTTO LF. Filosofia do Direito; os conceitos fundamentais e a tradição jusnaturalista. - Porto Alegre: Livraria do Advogado Editora. 2010.

3. BICUDO HP. Direitos humanos e sua proteção. - São Paulo: FTD, 1997. - (Coleção juristas da atualidade/ coordenação Hélio Bicudo).

4. BRANDÃO DS. Vida: O primeiro Direito da Cidadania. Gráfica e Editora Bandeirantes Ltda., Goiânia. 2005.

5. BRASIL. Constituição Federal de 1988. Promulgada em 5 de outubro de 1988. Disponível em <http://www.planalto.gov.br/ccivil_03/constituicao/constituicao.htm> acesso em 10/03/2020.

6. BRASIL. Lei oㅜ 10.406, de 10 de janeiro de 2002. Institui o Código Civil. Diário Oficial da União: seção 1, Brasília, DF, ano 139, n. 8, p. 1-74, 11 jan. 2002. Disponível em <http://www.planalto.gov.br/ccivil_03/leis/2002/l10406.htm acesso> em 10/03/2020

7. BRASIL. Código Penal. Decreto-Lei 2.848 de 7 de dezembro de 1940. Diário Oficial da República Federativa do Brasil, 31 de dezembro de 1941.

8. CARVALHO KG. Direito Constitucional. 15 edição, rev. atual. E ampl. - Belo Horizonte: Del Rey, 2009

9. D'AGOSTINO F. Bioética segundo o enfoque da Filosofia do Direito. Tradução de Luisa Rabone; Editora Unisinos, coleção Dike, 2006. 
10. DINIZ MH. O estado atual do biodireito. - 4 Ed. ver. E atual. Conforme a lei 11.105/2005. - Saraiva, 2007.

11. ESPINOSA J. Questões de Bioética, Editora Quadrante. São Paulo. 1998. p. 64.

12. KANT I. Fundamentação da metafísica dos costumes e outros escritos; tradução de Leopoldo Holzbach - São Paulo: Martin Claret, 2004.

13. KACZOR C. A ética do aborto: direitos das mulheres, vida humana e a questão da justiça. Tradução Antônio José Maria de Abreu. São Paulo: Edições Loyola, 2014

14. LEÃO P. Vida: O primeiro Direito da Cidadania. Gráfica e Editora Bandeirantes Ltda., Goiânia. 2005,

15. LEE P., GEORGE RP. Body-Self Dualism in contemporary Ethics and Politics. Cambridge, 2008.

16. LICHFIELD M. Bebês para queimar: a indústria do aborto na Inglaterra. Por Michael Lichfield e Susan Kentish; traduziu: Euclides Carneiro da Silva. São Paulo, Ed. Paulinas, 1977.

17. GEORGE RP. Conscience and its enemies: confronting the dogmas of liberal secularism. $2^{\mathrm{a}}$ ed. Washington: ISI Books. 2016.

18. GEORGE RP, TOLLEFSEN C. Embryo, a Defense of Human Life. $2^{\mathrm{a}}$ edition, Published by the Witherspoon Institue, 2011.

19. MARTINS AS. Homo sacer, sujeitos abandonados ao crime. Disponível em<http://www.appoa.com.br/correio/edicao/240/homo_sacer_sujeitos_abandonados_ao_cri me/158>. Acesso em 26/11/2016.

20. MARTINS IGS (coordenação). Direito Fundamental à Vida. São Paulo: Quartier Latin/ Centro de Extensão Universitária, 2005. Art. Umas poucas palavras sobre o direito à vida.

21. MARTINS IGS. Uma breve introdução ao direito. - São Paulo: Editora Revista dos tribunais, 2010.

22. MARTINS RVS. Aborto no direito comparado: Uma reflexão crítica. Belém: CEJUP, 1991.

23. NALINI JR. A evolução protetiva da vida na constituição brasileira. In A Vida dos Direitos Humanos; Sergio Antônio Fabris Editor; Porto Alegre. 1999

24. PIMENTEL MMG, apud in BICUDO HP. Direitos humanos e sua proteção. - São Paulo: FTD, 1997. - (Coleção juristas da atualidade/ coordenação Hélio Bicudo).

25. RODRIGUES FILHO AMM. A problemática da personalidade jurídica do nascituro e o aborto de feto anencéfalo. Trabalho de Conclusão de Curso de graduação em Direito. Universidade Federal do Pará, Belém-PA 2018.

26. STF, ADPF 54, rel. Min. Marco Aurélio, Pleno, j. 12.04.2012.

27. STF, ADIn 3.310, rel. Min. Ayres Britto, Plenário. J. 29.05.2008, DJe 28.05.2010.

28. TEDESCHI SE. EI Waterloo del Código Civil Napoleónico. Una mirada crítica a los fundamentos del Derecho Privado Moderno para la construcción de sus nuevos principios generales. In: COURTIS, Christian (compilador). Desde otra mirada: texto de teoria crítica del derecho. Buenos Aires: Eudeba, 2001.

29. URUGUAY, Tribunal de Apelaciones de Familia de Primer Turno, DFA-0010-000216/2017. Disponível em $<$ http://www.poderjudicial.gub.uy/images/2017/resoluciones_2017/sent_09-0317_taf1_amparo_ive_jueza_book.pdf> acesso em 09 de março de 2020. 